\title{
Reciprocal Changes in the Firing Probability of Lateral and Central Medial Amygdala Neurons
}

\author{
Dawn R. Collins and Denis Paré \\ Laboratoire de Neurophysiologie, Département de Physiologie, Faculté de Médecine, Université Laval, \\ Québec, Canada G1K 7P4
}

The amygdala is essential for classical fear conditioning. According to the current model of auditory fear conditioning, the lateral nucleus is the input station of the amygdala for conditioned auditory stimuli, whereas the central nucleus is the output station for conditioned fear responses. Yet, the lateral nucleus does not project to the central medial nucleus, where most brainstem projections of the amygdala originate. The available evidence suggests that the basal nuclei could transmit information from the lateral to the central medial nucleus. However, interposed between the basolateral complex and the central nucleus are clusters of GABAergic cells, the intercalated neurons, which receive inputs from the lateral and basal nuclei and contribute a massive projection to the central medial nucleus. Because it is impossible to predict the consequences of these connections, we correlated the spontaneous and auditory-evoked activity of multiple simultaneously recorded neurons of the lateral, basal, and central nuclei. The spontaneous activity of lateral and basolateral neurons was positively correlated to that of central lateral cells but negatively correlated to that of central medial neurons. In response to auditory stimuli, the firing probability of lateral and central medial neurons oscillated in phase opposition, initially being excited and inhibited, respectively. In light of previous anatomical findings, we propose that the lateral nucleus exerts two indirect actions on central medial neurons: an excitation via the basal nuclei and an inhibition via intercalated neurons.

Key words: amygdala; fear conditioning; multisite recording; lateral amygdala; intra-amygdaloid pathways; intercalated cell masses
Accumulating evidence implicates the amygdala in aversive learning (Davis, 1992; LeDoux, 1995). A model commonly used to study this form of learning is pavlovian fear conditioning. In this paradigm, an initially neutral sensory stimulus, such as a tone [conditioned stimulus (CS)], is paired to a noxious unconditioned stimulus (US), usually a footshock. After a few pairings, the CS alone elicits the behavioral and autonomic responses associated with the US.

Much data suggests that the lateral nucleus is the input site of the amygdala for the CS, whereas the central amygdaloid (CE) nucleus is the output station for conditioned fear responses. On the input side, the lateral nucleus receives direct auditory inputs from the thalamus and cortex (LeDoux et al., 1985, 1990b; Turner and Herkenham, 1991; Mascagni et al., 1993). Moreover, lesioning the lateral nucleus prevents auditory fear conditioning (LeDoux et al., 1990a). On the output side, most brainstem projections of the amygdala originate from the medial sector of the $\mathrm{CE}$ nucleus $\left(\mathrm{CE}_{\mathrm{M}}\right)$ (Hopkins and Holstege, 1978; Veening et al., 1984). Accordingly, lesions of the CE nucleus (Kapp et al., 1979; Gentile et al., 1986; Iwata et al., 1986; Zhang et al., 1986; Hitchcock et al., 1989) or its brainstem and hypothalamic targets (Francis et al., 1981; LeDoux et al., 1988) abolish conditioned fear responses.

At present, it is unclear how CS-evoked activity is relayed from

Received Sept. 17, 1998; revised Oct. 26, 1998; accepted Oct. 29, 1998.

This work was supported by Medical Research Council Grant MT-11562. We thank Dr. Eric J. Lang for comments on an earlier version of this manuscript and P. Giguère and D. Drolet for their technical assistance.

Correspondence should be addressed to Denis Paré, Laboratoire de Neurophysiologie, Département de Physiologie, Faculté de Médecine Université Laval, Québec, Canada G1K 7P4.

Copyright (C) 1999 Society for Neuroscience $\quad 0270-6474 / 99 / 190836-09 \$ 05.00 / 0$ the lateral to the $\mathrm{CE}_{\mathrm{M}}$ nucleus. Indeed, the lateral nucleus does not project to the $\mathrm{CE}_{\mathrm{M}}$ in rats and cats (Krettek and Price, 1978; Smith and Paré, 1994; Pitkanën et al., 1995) but contributes glutamatergic projections (Smith and Paré, 1994) to the lateral sector of the $\mathrm{CE}$ nucleus $\left(\mathrm{CE}_{\mathrm{L}}\right)$, as well as to the basolateral $(\mathrm{BL})$ and basomedial (BM) nuclei (Krettek and Price, 1978; Stefanacci et al., 1992; Smith and Paré, 1994; Pitkanën et al., 1995). Projection neurons of the basal nuclei could transmit CS-evoked lateral activity to the $\mathrm{CE}_{\mathrm{M}}$, because their axons form asymmetric synaptic contacts with $\mathrm{CE}_{\mathrm{M}}$ cells (Paré et al., 1995b). However, this simple scenario is complicated by the fact that the $\mathrm{CE}_{\mathrm{L}}$ nucleus contributes a small GABAergic projection to the $\mathrm{CE}_{\mathrm{M}}$ nucleus (Grove, 1988; Paré and Smith, 1993b). In addition, interposed between the BL complex and CE nucleus is a string of GABAergic cell clusters (Paré and Smith, 1993a), the intercalated cell masses (ICMs), which project to the $\mathrm{CE}_{\mathrm{M}}$ (Paré and Smith, 1993b) and are contacted by the axon collaterals of lateral and BL neurons en route to the CE nucleus (Millhouse, 1986). Thus, excitation of lateral amygdala neurons could have a mixed action on $\mathrm{CE}_{\mathrm{M}}$ cells: inhibitory via $\mathrm{CE}_{\mathrm{L}}$ and ICM neurons and excitatory via the basal nuclei.

Here, this issue was examined by correlating the spontaneous and auditory-evoked activity of multiple simultaneously recorded lateral, basal, and $\mathrm{CE}$ neurons. Our results revealed that the spontaneous and auditory-evoked activity of lateral amygdala neurons is negatively correlated to that of $\mathrm{CE}_{\mathrm{M}}$ neurons but positively correlated to that of $\mathrm{BL}$ and $\mathrm{CE}_{\mathrm{L}}$ neurons.

\section{MATERIALS AND METHODS}

Electrode implantation. Experiments were performed in three adult cats $(2.5-3.5 \mathrm{~kg})$ that were chronically implanted in a stereotaxic position under deep barbiturate anesthesia. We chose this species because the 

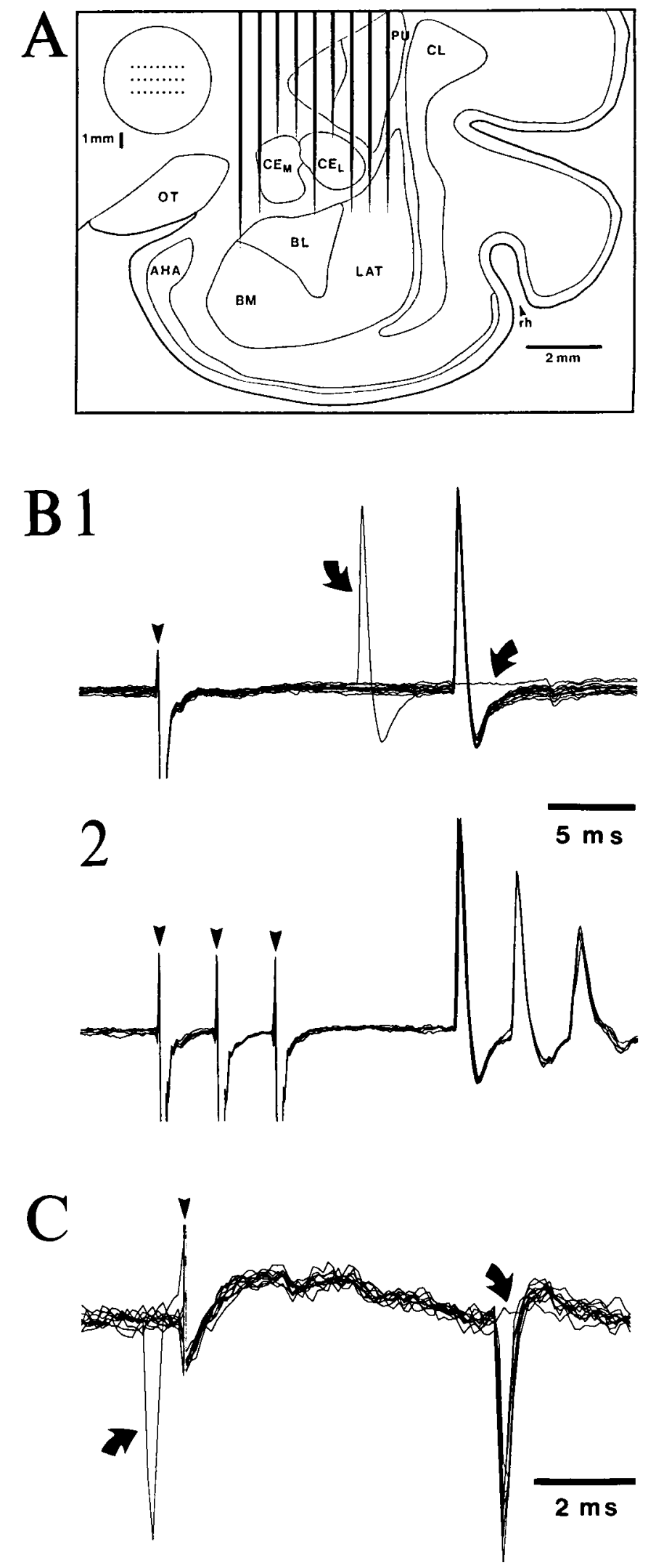

Figure 1. Recording method and physiological identification of projection cells. $A$, Scheme illustrating one of the microelectrode configurations used to obtain simultaneous extracellular recordings of amygdala neurons. Only one of the three electrode rows is shown. Inset in top left shows a top view of the electrode array. The length of the different electrodes large size of cat brains facilitates the placement of multiple microelectrodes in different nuclei of the amygdala. Furthermore, auditory fear conditioning can be induced in cats (Oleson et al., 1972, 1973, 1975; Weinberger et al., 1984), and cryogenic blockade of the cat CE nucleus reversibly abolishes conditioned fear responses (Zhang et al., 1986).

The anesthesia was induced with ketamine $(15 \mathrm{mg} / \mathrm{kg}$, i.m.), and atropine sulfate $(0.05 \mathrm{mg} / \mathrm{kg}$, i.m. $)$ was administered to prevent secretions. Then, sodium pentobarbital was injected gradually $(15-25 \mathrm{mg} / \mathrm{kg}$, i.v.; Somnotol). Two silver-ball electrodes were fixed into the supraorbital cavity with dental cement to record eye movements [electro-oculography (EOG)]. To monitor electromyographic (EMG) activity, two Tefloninsulated wires were inserted in the neck muscles. The electroencephalogram (EEG) was recorded with stainless steel screws anchored to the bone overlying the pericruciate area.

The bone overlying the amygdaloid complex was removed on one side, and the dura mater was opened. Then, an array of 21-27 tungsten electrodes (three rows of seven to nine electrodes) was lowered until the electrodes reached the dorsal aspect of the amygdala (Fig. $1 \mathrm{~A}$ ). These electrodes (Frederick Haer Co., Brunswick, ME) had a maximal outer diameter of $80 \mu \mathrm{m}$ and an impedance of $2-6 \mathrm{M} \Omega$ at $1 \mathrm{kHz}$. To construct the array, small holes were drilled in a circular Teflon block, and the electrodes were inserted into them. The length of the different electrodes was adjusted so that neuronal recordings could be simultaneously obtained from different nuclei of the amygdala (Fig. $1 A$, electrode configuration). The Teflon block was inserted in a tightly fitting sleeve, which was cemented to the bone. During the recording sessions, the electrodes could be lowered by means of a micrometric screw pushing on the Teflon block.

To identify projection cells of the $\mathrm{BL}$ complex and $\mathrm{CE}_{\mathrm{M}}$ nucleus physiologically, stimulating electrodes were stereotaxically inserted in the perihinal cortex (Fig. 2C), as well as in the brainstem (Fig. 2B). To maximize the likelihood of eliciting antidromic responses from $\mathrm{CE}_{\mathrm{M}}$ neurons, brainstem stimulating electrodes were inserted just dorsal to the substantia nigra pars reticulata, where $\mathrm{CE}_{\mathrm{M}}$ fibers en route to the pons and medulla are located (Hopkins and Holstege, 1978) (Fig. 2B). Electrical stimuli consisted of $0.05-0.2 \mathrm{msec}$ pulses of $0.1-1.0 \mathrm{~mA}$ delivered at various frequencies. Cells that could be antidromically activated from one of these sites were formally identified as projection neurons (Fig. $1 B)$. The criteria used for antidromic identification were fixed response latency, collision with spontaneously or orthodromically evoked action potentials, and ability to follow high-frequency stimulation. These physiological identifications were complemented with histological controls as described below.

Finally, four screws were cemented to the skull. These screws were later used to fix the cat's head in a stereotaxic position without pain or pressure. Bicillin (intramuscularly daily for $3 \mathrm{~d}$ ) and buprenorphine (0.03 $\mathrm{mg} / \mathrm{kg}$, i.m., every $12 \mathrm{hr}$ for $24 \mathrm{hr}$ ) were administered postoperatively. Recording sessions began 6-8 d after the surgery. Between experimental sessions, the animals slept, ate, and drank ad libitum.

Recording and stimulating methods. During the recording sessions, the EEG, EOG, and EMG signals were used to distinguish behavioral states of vigilance on the basis of previously described electrographic criteria (Steriade and Hobson, 1976). All recordings described in this study were obtained during the waking state, as identified by a desynchronized EEG, voluntary eye movements, and the presence of muscle tone. At the beginning of each recording session, the electrode array was lowered $80-160 \mu \mathrm{m}$. Thirty minutes later, each recording site was examined for units with a high signal-to-noise ratio $(\geq 3)$. At this stage, both sponta-

was adjusted to allow simultaneous recordings from the BL complex and central nucleus. The scheme shows the intended position of the microelectrodes at the beginning of the experiments. The array was lowered $80-160 \mu \mathrm{m}$ before each recording session. $B$, Antidromic invasion of a $\mathrm{CE}_{\mathrm{M}}$ neuron from the brainstem. $C$, Neuron of the lateral nucleus backfired from the perirhinal cortex. Data were digitally filtered $(100 \mathrm{~Hz}$ to 10 $\mathrm{kHz}$ ). Arrowheads indicate stimulation artifacts. Curved arrows in $B 1$ and $C$ point to spontaneously occurring action potentials colliding with antidromic responses. Note the fixed latency of antidromic spikes and their ability to follow high-frequency stimulation (B2). $A H A$, Amygdalohippocampal area; $B L$, basolateral nucleus; $B M$, basomedial nucleus; $C E_{M}$, medial sector of the central nucleus; $C E_{L}$, lateral sector of the central nucleus; $C L$, claustrum; $L A T$, lateral nucleus; $O T$, optic tract; $P U$, putamen; $r h$, rhinal sulcus. 


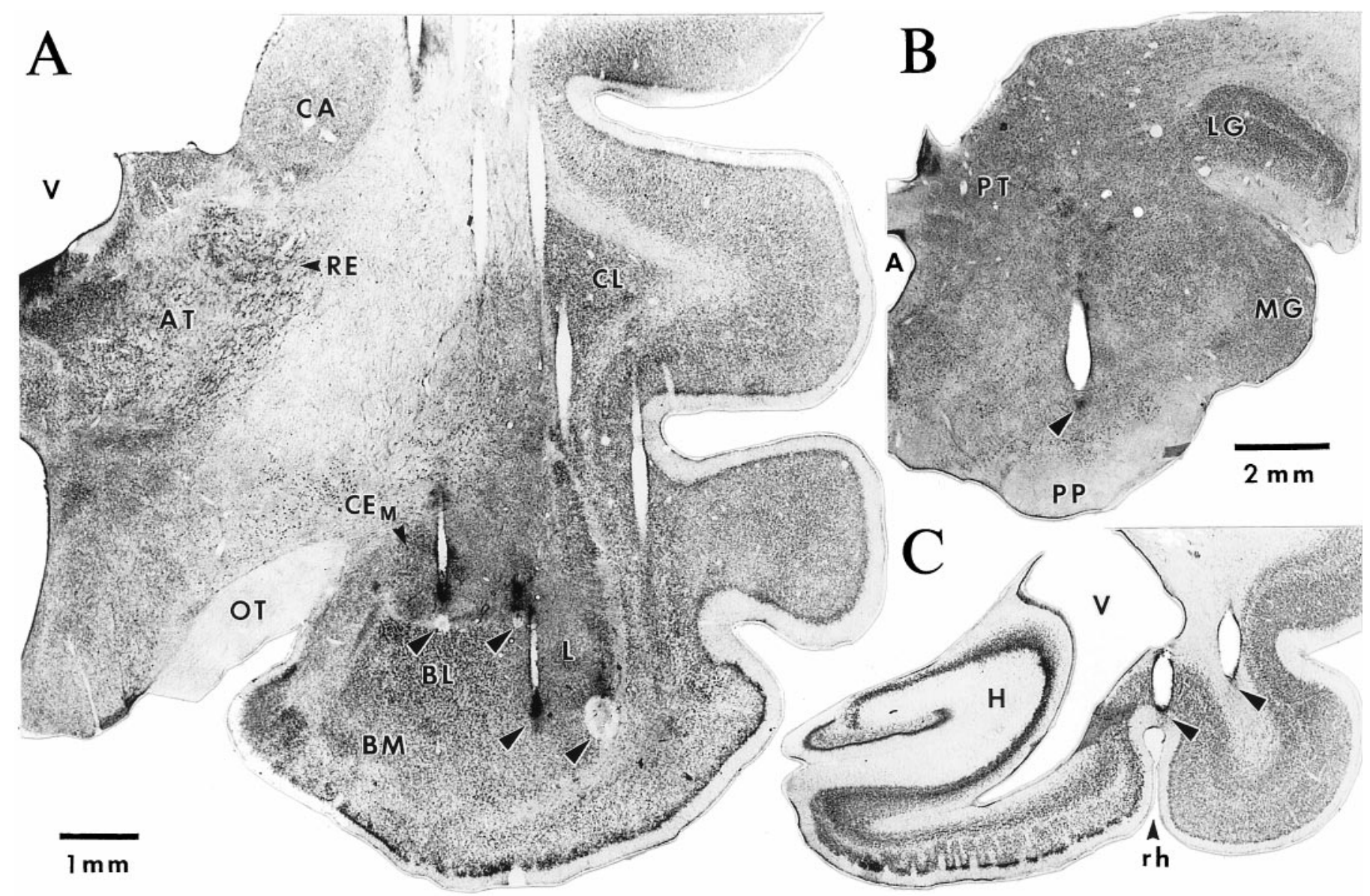

Figure 2. Histological determination of recording and stimulating sites. $A$, Frontal section showing the traces left by one row of microelectrodes. Note that the plane of the section is not exactly parallel to the trajectory of the microelectrodes. For some electrodes, the last recording site was marked with small electrolytic lesions (arrowheads). Left to Right, Arrowheads point to electrolytic lesions performed at the end of tracks through the $\mathrm{CE}_{\mathrm{M}}$, $\mathrm{CE}_{\mathrm{L}}$, and lateral (two rightmost lesions) nuclei. $B, C$, Photomicrographs in which arrowheads point to the traces left by the tip of stimulating electrodes just dorsal to the substantia nigra $(B)$ and in the perirhinal region $(C)$. $A$, Aqueduct; $A T$, anterior thalamic nuclei; $B L$, basolateral nucleus; $B M$, basomedial nucleus; $C A$, caudate nucleus; $C E_{M}$, medial sector of the central nucleus; $C L$, claustrum; $H$, hippocampal formation; $L$, lateral nucleus; $L G$, lateral geniculate nucleus; $M G$, medial geniculate nucleus; $O T$, optic tract; $P P$, pes pedunculi; $P T$, pretectal nuclei; $P U$, putamen; $R E$, reticular thalamic nucleus; $r h$, rhinal sulcus; $V$, ventricle.

neous activity and electrically evoked responses were examined, because amygdala neurons have extremely low firing rates (Gaudreau and Paré, 1996; Paré and Gaudreau, 1996). As a rule, four to six cells with a signal-to-noise ratio ranging from 3 to 15 could be found. However, it should be pointed out that this recording method was biased toward cells with higher firing rates. The spontaneous and evoked activity of the selected neurons was observed on a digital oscilloscope, printed on a chart recorder, digitized, and stored on tape. Auditory stimuli consisted of $1 \mathrm{sec}$ tones of $100 \mathrm{~Hz}$ to $12 \mathrm{kHz}$ at $80 \mathrm{~dB}$. These auditory stimuli did not elicit a startle response as determined by observing the behavior of the cat and the EMG of neck muscles.

Identification of recording sites. Approximately 30 recording sessions were performed with each animal (one per day). Then, the animals were deeply anesthetized with sodium pentobarbital, and selected recording sites were marked with electrolytic lesions $(0.5 \mathrm{~mA}$ for $5 \mathrm{sec})$. After this, the animals were perfused with $500 \mathrm{ml}$ of a cold saline solution $(0.9 \%)$, followed by 11 of a fixative containing $2 \%$ paraformaldehyde and $1 \%$ glutaraldehyde in $0.1 \mathrm{~m}$ PBS, $\mathrm{pH}$ 7.4. The brains were later sectioned on a vibrating microtome (at $80 \mu \mathrm{m}$ ) and stained with thionin to verify the position of the recording (Fig. $2 A$ ) and stimulating (Fig. $2 B, C$ ) electrodes. The microelectrode tracks were reconstructed by combining micrometer readings with the histological controls. Despite the high number of electrodes, it was easy to determine the position of all recorded neurons, because the relative position of the electrodes was known. The data were only included in the analyses after histological determination of the recording sites.
Analysis. Analyses were performed off-line with the software IGOR (Wavemetrics) and home-made software running on Macintosh microcomputers. Spikes were detected with a window discriminator, and firing rates were computed for long epochs of quiet waking $(2-3 \mathrm{~min})$. The auditory responsiveness of recorded neurons was studied by computing peristimulus histograms. In addition, we computed cross-correlation matrices for all sets of simultaneously recorded neurons.

\section{RESULTS}

\section{Database and neuronal identification}

A total of 546 cells with a signal-to-noise ratio $\geq 3$ were recorded in this study. Histological controls (Fig. $2 A$ ) revealed that 477 of these cells were located in the amygdala (lateral nucleus, $n=206$; BL nucleus, $n=129 ; \mathrm{CE}_{\mathrm{L}}$ nucleus, $n=111 ; \mathrm{CE}_{\mathrm{M}}, n=31$ ) and 69 in surrounding structures. Of the latter group, 48 cells were recorded in the perirhinal cortex. In agreement with previous findings indicating that the BL complex projects to the parahippocampal cortices but the CE nucleus does not (Krettek and Price, 1977), 25\% of neurons in the BL complex could be antidromically invaded from the parahippocampal cortices (latency, $8.6 \pm 0.65 \mathrm{msec}$ ) (Fig. 1) but none in the CE nucleus. Conversely, $68 \%$ of $\mathrm{CE}_{\mathrm{M}}$ neurons could be antidromically invaded from the 
brainstem (latency, $19 \pm 1.62 \mathrm{msec}$ ) compared with $2 \%$ in the $\mathrm{BL}$ complex. This difference is consistent with anatomical data indicating that most brainstem projections of the amygdala originate from the $\mathrm{CE}_{\mathrm{M}}$ nucleus (Hopkins and Holstege, 1978). In addition, the long latency of antidromic responses to brainstem stimuli is in agreement with previous findings (Pascoe and Kapp, 1985).

\section{Firing rates and selection of neurons}

In agreement with previous findings (Pascoe and Kapp, 1985; Bordi et al., 1993; Paré and Gaudreau, 1996), most neurons of the amygdala recorded in this study had low spontaneous firing rates, generally below $1 \mathrm{~Hz}\left(\mathrm{BL}, 86 \%\right.$; lateral, 76\%; $\mathrm{CE}_{\mathrm{L}}, 70 \% ; \mathrm{CE}_{\mathrm{M}}$, $62 \%$ ). This contrasted with the perirhinal cortex in which most cells $(65 \%)$ fired above $1 \mathrm{~Hz}$. Consistent with this, the median firing rates of amygdala neurons ranged between 0.3 and $0.7 \mathrm{~Hz}$. However, because our samples contained a few neurons that discharged tonically at elevated rates, average firing frequencies were somewhat higher than median rates $(\mathrm{BL}, 0.6 \pm 0.01 \mathrm{~Hz}$; lateral, $0.9 \pm 0.02 \mathrm{~Hz} ; \mathrm{CE}_{\mathrm{L}}, 1.2 \pm 0.03 \mathrm{~Hz} ; \mathrm{CE}_{\mathrm{M}}, 1.2 \pm 0.07 \mathrm{~Hz}$ ).

Nuclei of the BL complex (lateral, BL, and BM nuclei) contain two main cell types (McDonald, 1992). The majority of cells $(85 \%)$ are spiny glutamatergic projection neurons, and a minority of cells are aspiny local-circuit neurons immunopositive for GABA (McDonald, 1985; McDonald and Augustine, 1993; Paré and Smith, 1993a). Thus, by chance alone, our sample of lateral and BL neurons should be primarily comprised of projection cells. Nevertheless, we attempted to further limit our analyses to BL projection cells, because they are the progenitor of internuclear BL projections (Smith and Paré, 1994; Paré et al., 1995b) and this study focuses on the relationships between the activity of different amygdaloid nuclei.

The criteria used here to distinguish projection cells from interneurons of the BL complex are based on a previous electrophysiological investigation in behaving cats (Paré and Gaudreau, 1996). In this study, all lateral and BL neurons that could be backfired from projection fields of the BL complex fired spontaneously at low rates, generally below $1 \mathrm{~Hz}$. In this same study, none of the cells with high spontaneous firing rates $(>10 \mathrm{~Hz})$ could be antidromically invaded from targets of the BL amygdala. Consequently, they were presumed to be local-circuit cells. This idea is supported by the results of intracellular studies in which the physiological and morphological properties of BL amygdaloid neurons were correlated (Washburn and Moises, 1992; Rainnie et al., 1993; Paré et al., 1995a; Lang and Paré, 1998). This approach revealed that aspiny neurons of the BL complex are endowed with intrinsic membrane properties allowing them to sustain high firing rates for prolonged periods of time (Washburn and Moises, 1992; Rainnie et al., 1993; Paré et al., 1995a; Lang and Paré, 1998). Thus, in the present study, all cells of the lateral and BL nuclei with high spontaneous firing rates $(>5 \mathrm{~Hz} ; 9.6 \%$ of our sample) were excluded from the analyses described below.

\section{Temporal relationship between the auditory-evoked activity of lateral, $C E$, and $B L$ neurons}

Because CE, lateral, and BL neurons have low firing rates and their responses to auditory stimuli habituate rapidly (Bordi and LeDoux, 1992), examining individual peristimulus histograms proved inadequate to study the nature (excitatory vs inhibitory) of auditory responses. To circumvent this difficulty, we added the responses of several cells to two different auditory stimuli (4-10 $\mathrm{kHz}, 1 \mathrm{sec}$ ), each presented 20 times, and computed population peristimulus histograms with $10 \mathrm{msec}$ bins. In addition, the auditory-evoked focal waves that were simultaneously recorded by the microelectrodes used for unit recordings were digitally filtered $(3-50 \mathrm{~Hz})$ and averaged. The results of these analyses are shown in Figure 3 for samples of neurons recorded in the $\mathrm{CE}_{\mathrm{M}}$ $(n=31$; Fig. $3 A), \mathrm{CE}_{\mathrm{L}}(n=111$; Fig. $3 B)$, lateral $(n=184$; Fig. $3 C)$, and BL ( $n=110$; Fig. $3 D)$ nuclei. The average focal waves are superimposed on the corresponding peristimulus histograms.

In agreement with anatomical findings indicating that the lateral nucleus receives direct auditory inputs from the thalamus (LeDoux et al., 1985, 1990b), neurons of the lateral nucleus (Fig. $3 C$ ) displayed the shortest latency responses to auditory stimuli, followed by those of the $\mathrm{CE}_{\mathrm{L}}, \mathrm{BL}$, and $\mathrm{CE}_{\mathrm{M}}$ nuclei (poststimulus bins $3,4,5$, and 7 , respectively). This determination was performed by identifying the first poststimulus bin to reach statistical significance $(p<0.05)$ in a one-tailed $t$ test (average prestimulus value \pm 1.64 times the corresponding SD). However, it should be pointed out that the differing latencies of auditory-evoked responses in these nuclei might not reflect the order of synaptic events but rather the influence of other factors, such as the differing strength of inputs, membrane potentials or intrinsic membrane properties.

The peak changes in firing probability, expressed in terms of prestimulus values, ranged from 1.5 in the BL nucleus to 2.5 in the $\mathrm{CE}_{\mathrm{L}}$ nucleus, with $\mathrm{CE}_{\mathrm{M}}$ and lateral neurons exhibiting intermediate values (2.2 and 2.1, respectively).

In the lateral, $\mathrm{CE}_{\mathrm{L}}$, and $\mathrm{BL}$ nuclei, auditory stimuli first evoked an increase in firing probability that coincided with a focal negativity (Fig. $3 B-D$ ). In contrast, in the $\mathrm{CE}_{\mathrm{M}}$ nucleus, auditory stimuli first produced a decrease in firing probability that coincided with a focal positivity (Fig. $3 A$ ). In fact, there was generally a consistent relationship between the changes in firing probability and the polarity of the focal waves in which negative and positive focal waves corresponded to increasing and decreasing firing probabilities, respectively. However, for unknown reasons, this rule did not apply to the signals recorded in the BL nucleus (Fig. 3D).

In addition, the changes in firing probability elicited by auditory stimuli were not constant but oscillatory in nature. For instance, the initial decreased firing of $\mathrm{CE}_{\mathrm{M}}$ neurons was followed by a phase of increased discharge probability. Thereafter, these two phases of decreased and increased firing probability recurred, with a progressively decreasing amplitude, at a frequency of $\sim 8-10 \mathrm{~Hz}$. A similar phenomenon was observed in the lateral nucleus, with the exception that the changes in firing probability were in phase opposition to those observed in the $\mathrm{CE}_{\mathrm{M}}$. This point is easier to observe in Figure 4 in which we superimposed a normalized version of the peristimulus histograms depicted in Figure 3, $A$ and $C$. In Figure 4, note the reciprocal relationship between the fluctuations in firing probability of lateral (thick line) and $\mathrm{CE}_{\mathrm{M}}$ (thin line) neurons.

Because many of the lateral, $\mathrm{CE}_{\mathrm{L}}$, and $\mathrm{CE}_{\mathrm{M}}$ neurons used for the analyses of Figures 3 and 4 were recorded simultaneously, we further analyzed the temporal relationships between the activity of lateral and CE neurons by computing cross-correlograms of auditory-evoked discharges for all available cell couples. To maximize the number of counts, auditory stimuli consisted of 30 tones of $1 \mathrm{sec}$ in duration, each presented five times, and increasing in frequency from 100 to $11,700 \mathrm{~Hz}$ in steps of $400 \mathrm{~Hz}$. Individual cross-correlograms were normalized to the number of spikes in the reference cell and averaged.

The results of this analysis are shown in Figure 5 for couples of lateral and $\mathrm{CE}_{\mathrm{M}}$ neurons $(n=16$; Fig. $5 A)$, lateral and $\mathrm{CE}_{\mathrm{L}}$ cells $(n=30$; Fig. $5 B)$, and lateral neurons $(n=32$; Fig. $5 C)$. The 

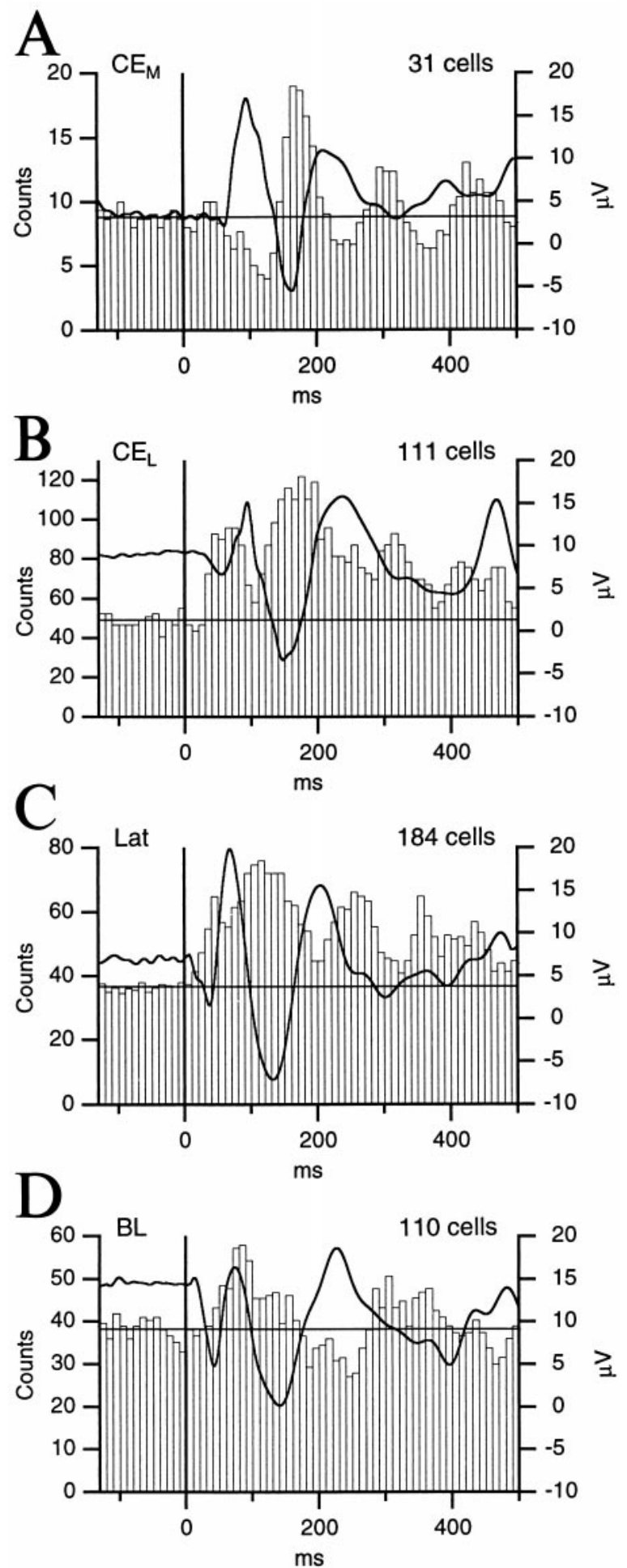

Figure 3. Auditory-evoked responses in the central nucleus and BL complex. Population peristimulus histograms of auditory-evoked discharges recorded in various amygdala nuclei (indicated in the top left of each panel). Each histogram was obtained by adding the response of several cells ( $n$ in top right of each panel) to two tones comprised between 4 and $10 \mathrm{kHz}$, each presented 20 times. Superimposed on each histogram is the auditory-evoked focal response picked up by the same electrodes during the unit recordings. The focal waves were digitally filtered between 3 and $50 \mathrm{~Hz}$. In each graph, the left axis refers to the histogram and the right one to the amplitude of focal waves. Vertical and horizontal lines indicate the onset of the auditory stimuli and the average number of counts before stimulation, respectively.

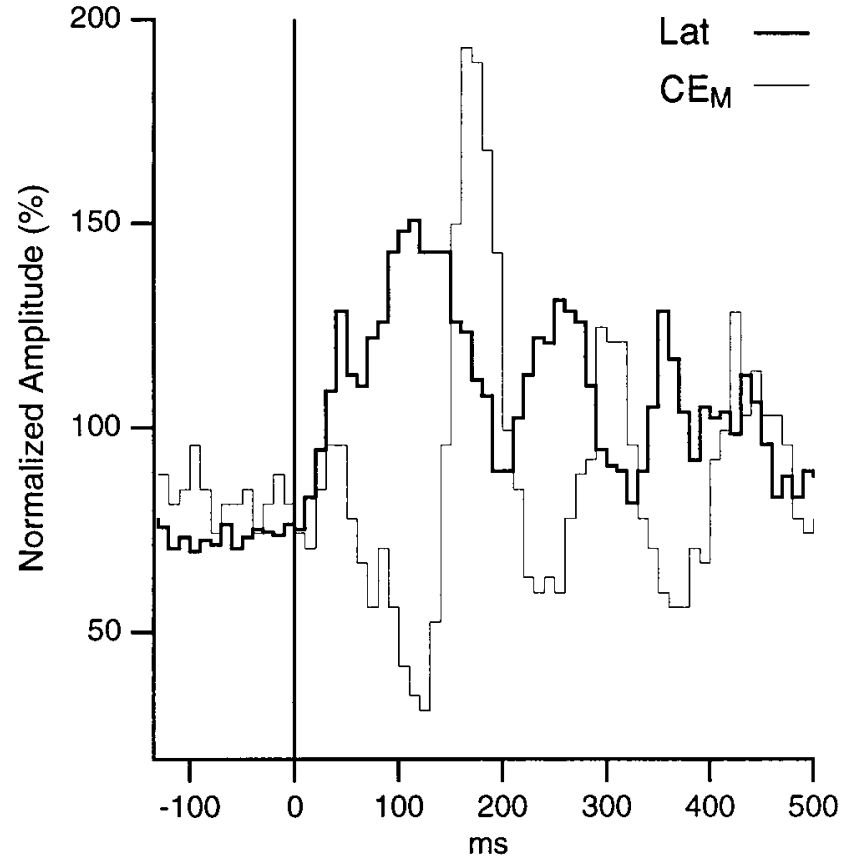

Figure 4. Reciprocal changes in the firing probability of lateral and $\mathrm{CE}_{\mathrm{M}}$ neurons during auditory stimulation. The peristimulus histograms of lateral (thick line) and $\mathrm{CE}_{\mathrm{M}}$ (thin line) neurons shown in Figure 3 were normalized so that the average bin values for the entire period is 100 and superimposed. A total of $31 \mathrm{CE}_{\mathrm{M}}$ and 184 lateral cells were used. Note that when the firing probability of lateral neurons increases, that of $\mathrm{CE}_{\mathrm{M}}$ neurons decreases and vice versa.

population correlogram of lateral versus $\mathrm{CE}_{\mathrm{M}}$ neuronal activity (Fig. $5 A$ ) is characterized by a central trough, at time 0 , flanked on both sides by one or more peaks with an interpeak interval of 110-120 msec. This is consistent with the poststimulus histograms shown in Figures 3 and 4 in which the firing probability of lateral and $\mathrm{CE}_{\mathrm{M}}$ neurons was shown to oscillate in phase opposition, at a frequency of $8-10 \mathrm{~Hz}$. In contrast, correlating the activity of lateral cell couples (Fig. $5 C$ ) or that of couples including lateral and $\mathrm{CE}_{\mathrm{L}}$ neurons (Fig. $5 B$ ) yielded population correlograms characterized by a central peak, indicating that the auditory responses of lateral and $\mathrm{CE}_{\mathrm{L}}$ neurons tended to coincide in time. The peak values of these various cross-correlograms were all larger than the average bin values plus $1.64 \mathrm{SD}$, the level required to reach statistical significance $(p<0.05)$ in a one-tailed $t$ test. In Figure $5 A-C$, the difference between the peaks and the average bin values were $1.9,2.3$, and 2.5 times the corresponding $\mathrm{SD}$, respectively.

In the three correlograms in Figure 5, it is noteworthy that the proportion of action potentials fired by the reference cells that were followed by discharges in the test cells in a $\pm 250 \mathrm{msec}$ window was low, the maximum bin value being $<7 \%$.

\section{Temporal relationship between the spontaneous activity of lateral, CE, and BL neurons}

To determine whether the relationship between the activity of the various cell groups during auditory responses applied to other conditions, we cross-correlated the spontaneous activity (2-3 min epochs) of cells located in interconnected nuclei of the amygdala during the waking state (Fig. 6). As in the above analysis (Fig. 5), individual cross-correlograms were normalized to the number of spikes in the reference cell and averaged. In particular, we com- 
A

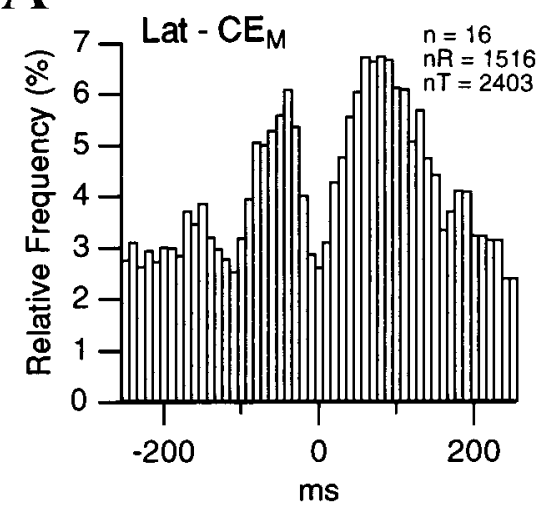

B

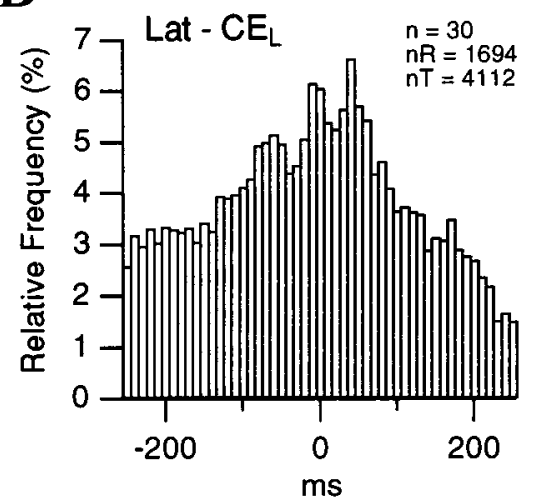

$\mathrm{C}$

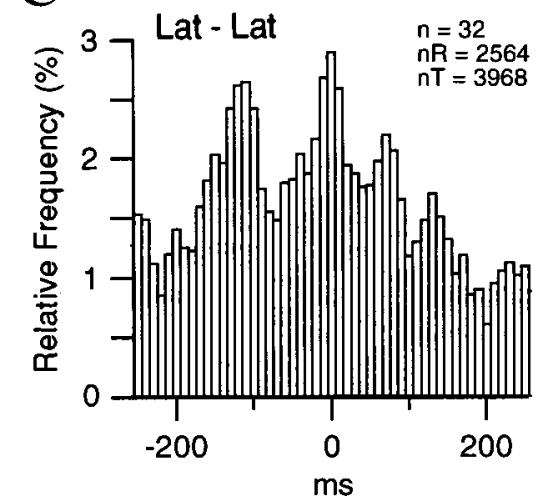

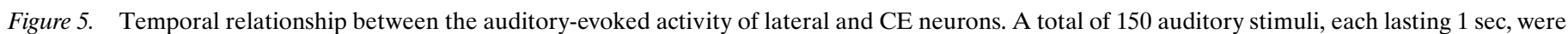

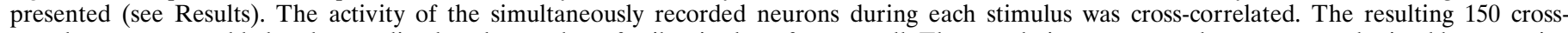

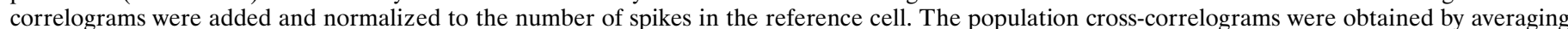

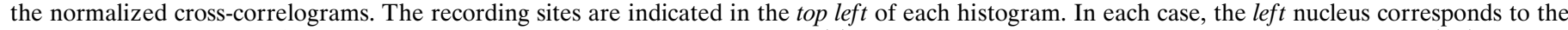

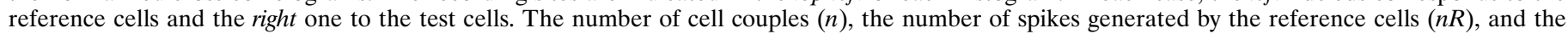
number of test cells $(n T)$ are indicated in the top right of each histogram.

pared the temporal relationship between the activity of lateral or $\mathrm{BL}$ neurons with respect to that of $\mathrm{CE}_{\mathrm{M}}$ (Fig. $\left.6 A, B\right)$ and $\mathrm{CE}_{\mathrm{L}}$ (Fig. 6C,D) neurons. In addition, we cross-correlated the unit activity within the lateral nucleus (Fig. $6 E$ ), as well as between lateral and $\mathrm{BL}$ neurons (Fig. $6 F$ ).

Consistent with the cross-correlograms of auditory-evoked activity (Fig. $5 A$ ), a negative correlation was found between the spontaneous activity of lateral and $\mathrm{CE}_{\mathrm{M}}$ neurons. This is evidenced by the trough observed around time 0 in Figure $6 A$. A similar phenomenon was observed when the spontaneous activity of $\mathrm{BL}$ and $\mathrm{CE}_{\mathrm{M}}$ neurons was cross-correlated (Fig. 6B). This contrasted with the positive correlation found between the activity of lateral and $\mathrm{BL}$ neurons with $\mathrm{CE}_{\mathrm{L}}$ cells (Fig. 6C,D, respectively), as well as among lateral neurons (Fig. $6 E$ ) and between lateral and $\mathrm{BL}$ neurons (Fig. $6 F$ ). The peak values of these various cross-correlograms reached statistical significance $(p<$ 0.05 ) in a one-tailed $t$ test. In Figure $6 A-F$, the difference between the peak values and the bin averages were $2.8,1.7,5.0,3.7,4.1$, and 3.8 times the corresponding SD, respectively.

It should be emphasized that the cells and focal waves used in the above analyses (Figs. 3-6) were recorded in three different cats. Qualitatively identical relationships were documented in each cat considered individually.

\section{DISCUSSION}

In recent years, our knowledge of the intrinsic circuitry of the amygdala has progressed considerably, thanks to a series of tracttracing studies (for review, see Pitkanën et al., 1997; Paré and Smith, 1998). However, wiring diagrams cannot provide a dynamic view of intra-amygdaloid interactions. Such knowledge can only be gained by relating the activity of multiple simultaneously recorded neurons in time. The present study is the first to analyze the relationships between the activity of multiple neurons recorded simultaneously in different nuclei of the amygdala. Whereas the activity of lateral and BL neurons was positively correlated to that of $\mathrm{CE}_{\mathrm{L}}$ cells, it was negatively correlated to the activity of $\mathrm{CE}_{\mathrm{M}}$ neurons. In addition, auditory stimuli elicited oscillations in the firing probability of lateral and $\mathrm{CE}_{\mathrm{M}}$ neurons, which were in phase opposition. In both nuclei, these changes in firing probability were consistently related to the polarity of focal waves in which negative and positive focal waves corresponded to increasing and decreasing firing probabilities, respectively. In the following account, we will consider these findings in light of the literature on intra-amygdaloid connections and suggest possible mechanisms for the reciprocal changes in firing probability observed between lateral and $\mathrm{CE}_{\mathrm{M}}$ neurons.

\section{The activity of lateral and BL neurons is positively correlated to that of $\mathrm{CE}_{\mathrm{L}}$ cells}

The positive correlation found between the spontaneous and auditory-evoked activity of lateral and BL neurons with that of $\mathrm{CE}_{\mathrm{L}}$ cells is consistent with recent anatomical findings, indicating that the axon terminals contributed by the lateral and BL nuclei to other nuclei of the amygdala are enriched in glutamate (Smith and Paré, 1994) and primarily form asymmetric synaptic contacts (Stefanacci et al., 1992; Smith and Paré, 1994; Paré et al., 1995b). These anatomical findings are also in agreement with the positive correlation found in the present study among presumed projection cells of the lateral nucleus, as well as between lateral and BL neurons.

\section{Lateral and $\mathrm{CE}_{\mathrm{M}}$ neurons display reciprocal changes in firing probability}

Considering that the lateral nucleus does not project to the $\mathrm{CE}_{\mathrm{M}}$ in cats and rats (Krettek and Price, 1978; Smith and Paré, 1994; Pitkanën et al., 1995), the auditory-evoked responses of $\mathrm{CE}_{\mathrm{M}}$ cells must be mediated by a common input to both nuclei or by the intra-amygdaloid targets of the lateral nucleus. The first possibility appears unlikely, because lateral and $\mathrm{CE}_{\mathrm{M}}$ cells displayed reciprocal changes in firing probability. Furthermore, the thalamic inputs conveying auditory information to the lateral nucleus do not contact $\mathrm{CE}_{\mathrm{M}}$ cells (LeDoux et al., 1990b). On the other hand, several intra-amygdaloid targets of the lateral nucleus project to the $\mathrm{CE}_{\mathrm{M}}$ nucleus (Krettek and Price, 1978; Smith and Paré, 1994; Pitkanën et al., 1995). Chiefly among them are the BL and BM nuclei (Paré et al., 1995b; Petrovich et al., 1996; Savander et al., 1995, 1996). As mentioned above, the ultrastructural features and glutamate immunoreactivity (Smith and Paré, 1994; Paré et al., 1995b) of the terminals contributed by the axons of lateral neurons to the basal nuclei, as well as those of BL and BM 
A

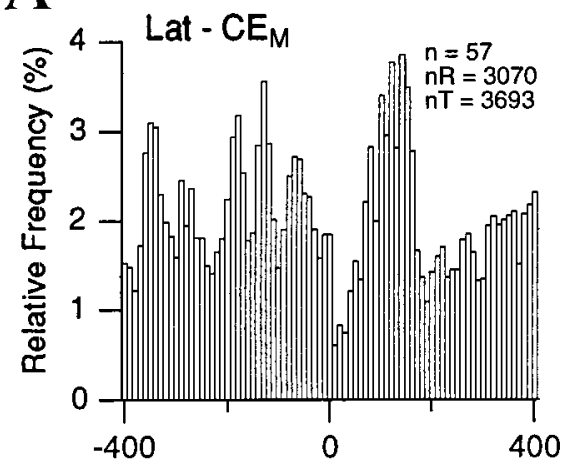

C

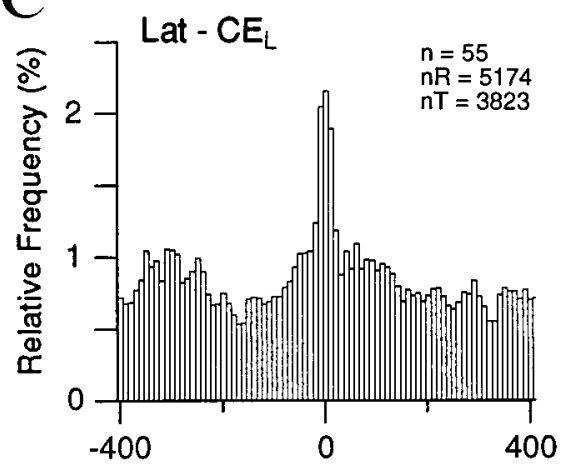

Figure 6. Temporal relationship between the spontaneous activity of lateral, BL, and CE neurons. Population cross-correlograms were computed for pairs of neurons recorded simultaneously in the sites indicated in the top left of each histogram. As in Figure 5, the left nucleus corresponds to the reference cells and the right one to the test cells. Spontaneous epochs were recorded in the waking state and lasted 2-3 min each. Periods contaminated by movements were not considered. Before averaging, the individual cross-correlograms were normalized to the number of spikes generated by the reference cell. The number of cell couples $(n)$, the number of spikes generated by the reference cells $(n R)$, and the number of test cells $(n T)$ are indicated in the top right of each histogram.

$\mathrm{E}$

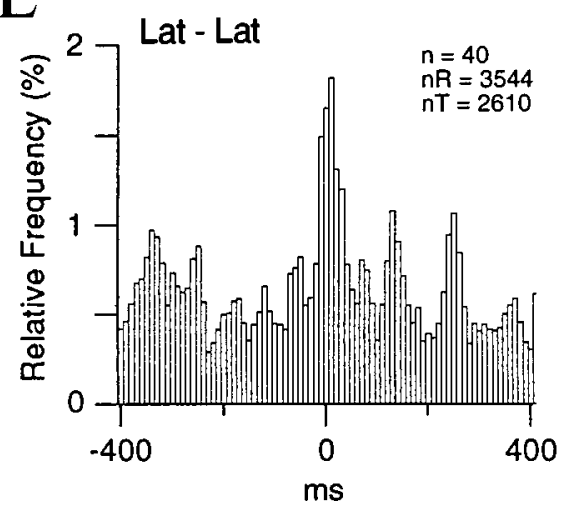

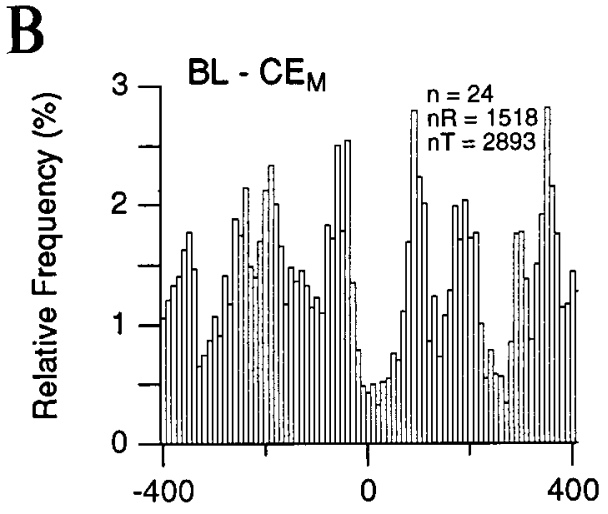

D

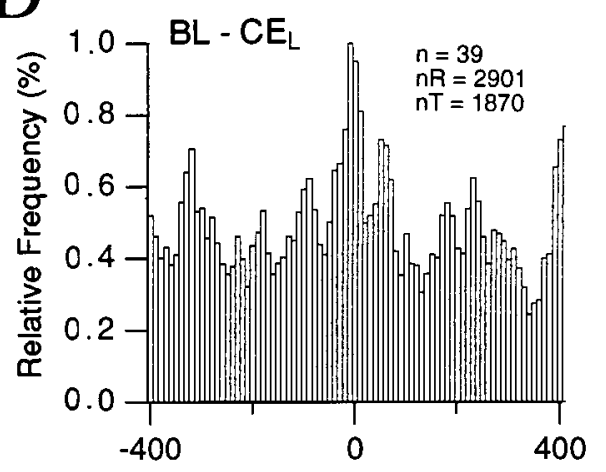

$\mathrm{F}$

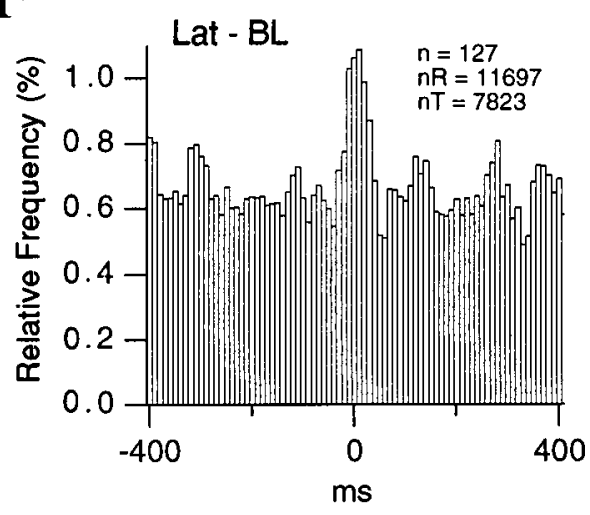

neurons to the $\mathrm{CE}_{\mathrm{M}}$ nucleus, suggest that there is a disynaptic excitatory glutamatergic projection between the lateral and $\mathrm{CE}_{\mathrm{M}}$ nuclei. What then is the origin of the phasic inhibition displayed by $\mathrm{CE}_{\mathrm{M}}$ cells in response to auditory stimuli?

\section{The ICMs as a GABAergic interface between the BL complex and $\mathrm{CE}_{\mathrm{M}}$}

In previous studies on the distribution of immunoreactivity for GABA or its synthetic enzyme (glutamate decarboxylase) in the $\mathrm{CE}_{\mathrm{M}}$ nucleus, paradoxical results were obtained: the $\mathrm{CE}_{\mathrm{M}}$ nucleus displayed one of the highest concentration of presumed GABAergic boutons but very few immunopositive somata (Nitecka and Ben-Ari, 1987; McDonald and Augustine, 1993; Paré and Smith, 1993a; Sun and Cassell, 1993). The possibility that these few GABAergic cells contributed most of the GABAergic boutons present in the $\mathrm{CE}_{\mathrm{M}}$ seemed unlikely. In addition, lesion studies argued against the existence of a major extrinsic GABAergic input to the amygdala (Le Gal La Salle et al., 1978), and BL lesions did not reduce the concentration of GABAergic terminals in the $\mathrm{CE}_{\mathrm{M}}$ (Sun and Cassell, 1993). Thus, two possibilities remained for the source of this inhibitory input: GABAergic cells of the $\mathrm{CE}_{\mathrm{L}}$ (Sun et al., 1994) or of the ICMs (Paré and Smith, 1993b).

We favor the possibility that the ICMs are the progenitor of this GABAergic input, because the $\mathrm{CE}_{\mathrm{L}}$ projection to the $\mathrm{CE}_{\mathrm{M}}$ is minor (Grove, 1988; Paré and Smith, 1993b). In keeping with this, we found no clear relationship between the spontaneous and auditory-evoked activity of $\mathrm{CE}_{\mathrm{M}}$ and $\mathrm{CE}_{\mathrm{L}}$ neurons in the present study (data not shown). Besides, the vast majority of intercalated neurons are immunopositive for GABA (Nitecka and Ben-Ari, 1987; McDonald and Augustine, 1993; Paré and Smith, 1993a), and they contribute a massive projection to the $\mathrm{CE}_{\mathrm{M}}$ nucleus (Paré and Smith, 1993b).

Little data are available concerning the afferents of the ICMs. However, the ICMs are located strategically to control the flow of information from the lateral and basal nuclei to the $\mathrm{CE}_{\mathrm{M}}$. First, they are embedded in the intermediate capsule, a fiber bundle 
separating the BL complex from the $\mathrm{CE}$ and medial nuclei. Second, Golgi observations suggest that axons coursing through the intermediate capsule emit collaterals that contact intercalated cells (Millhouse, 1986). Third, the axons of lateral and basal neurons cross the intermediate capsule on their way to the CE nucleus (Smith and Paré, 1994; Paré et al., 1995b) and probably contact intercalated neurons (Millhouse, 1986).

In light of these considerations, we hypothesize that projection neurons of the lateral and basal nuclei excite intercalated cells when their axons cross the intermediate capsule, thus generating a feed-forward inhibition in $\mathrm{CE}_{\mathrm{M}}$ cells. Activation of lateral projection cells would thus have a dual effect on $\mathrm{CE}_{\mathrm{M}}$ neurons: excitatory via the basal nuclei and inhibitory via intercalated neurons. Although these two actions should affect $\mathrm{CE}_{\mathrm{M}}$ cells more or less simultaneously, our data suggests that the inhibitory effects are initially more potent, because their firing probability first decreased in response to auditory stimuli. If this is the case, why isn't the firing probability of $\mathrm{CE}_{\mathrm{M}}$ cells persistently decreased below prestimulus values when that of lateral cells remain above baseline firing rates? The answer to this may reside in the intrinsic membrane properties of intercalated neurons themselves. Assuming that like most mammalian neurons, intercalated cells are endowed with voltage- and/or calcium-dependent potassium conductances (Llinás, 1988), it is likely that they will undergo a period of hyperpolarization after suprathreshold depolarization by lateral afferents. By the same token, the active properties of $\mathrm{CE}_{\mathrm{M}}$ cells may contribute to the post-inhibitory increase in firing probability evidenced in our study. Indeed, Schiess et al. (1993) have a observed that a proportion of $\mathrm{CE}$ neurons can generate rebound spikes at the offset of hyperpolarizing current pulses. Moreover, A-type $\mathrm{K}^{+}$currents could delay the post-inhibitory rebound firing of $\mathrm{CE}_{\mathrm{M}}$ cells observed during auditory stimuli.

At present, it is unclear why the auditory-evoked activity of lateral neurons is rhythmic. The absence of projections from the $\mathrm{CE}_{\mathrm{M}}$ to the lateral nucleus suggests that the rhythmicity arises in the lateral nucleus itself or in one of its inputs. This input (e.g., from the thalamus or cortex) could also contact intercalated cells. In any event, the intrinsic propensity of lateral neurons to generate voltage-dependent oscillations in the juxtathreshold range of membrane potentials may be a contributing factor (Paré et al., 1995a; Pape and Driesang, 1998; Pape et al., 1998). Another nonexclusive possibility is that the reciprocal connections between the lateral and BM nuclei (Paré et al., 1995b; Savander et al., 1997) play a critical role in this respect. Future studies should examine these issues.

\section{Implications for fear conditioning}

So far, most studies on the synaptic mechanisms underlying classical fear conditioning have focused on changes in glutamatergic transmission taking place in the amygdala (Chapman et al., 1990; Huang and Kandel, 1998; Li et al., 1998). In comparison, the possibility that changes in the intrinsic inhibitory circuitry of the amygdala might be involved in classical fear conditioning has received comparatively little attention (for a notable exception, see Mahanty and Sah, 1998). The presence of a GABAergic interface between the input station of the amygdala, the lateral nucleus, and its main source of brainstem projections, the $\mathrm{CE}_{\mathrm{M}}$ nucleus, suggests that an additional manner to modulate the throughput of the amygdala during fear conditioning would be to regulate the activity of ICM neurons.

\section{REFERENCES}

Bordi F, LeDoux J (1992) Sensory tuning beyond the sensory system: an initial analysis of auditory response properties of neurons in the lateral amygdaloid nucleus and overlying areas of the striatum. J Neurosci 12:2493-2503.

Bordi F, LeDoux J, Clugnet MC, Pavlides C (1993) Single-unit activity in the lateral nucleus of the amygdala and overlying areas of the striatum in freely behaving rats: rates, discharge patterns, and responses to acoustic stimuli. Behav Neurosci 107:757-769.

Chapman PF, Kairiss EW, Keenan CL, Brown TH (1990) Long-term synaptic potentiation in the amygdala. Synapse 11:310-318.

Davis M (1992) The role of the amygdala in fear and anxiety. Annu Rev Neurosci 15:353-373.

Francis J, Hernandez LL, Powell DA (1981) Lateral hypothalamic lesions: effects on pavlovian cardiac and eyeblink conditioning in the rabbit. Brain Res Bull 6:155-163.

Gaudreau H, Paré D (1996) Projection cells of the lateral nucleus are virtually silent throughout the sleep-waking cycle. J Neurophysiol 75:1301-1305.

Gentile CG, Jarrell TW, Teich AH, McCabe PM, Schneiderman N (1986) The role of amygdaloid central nucleus in differential pavlovian conditioning of bradycardia in rabbits. Behav Brain Res 20:263-276.

Grove EA (1988) Neural associations of the substantia innominata in the rat: afferent connections. J Comp Neurol 277:315-346.

Hitchcock JM, Sananes CB, Davis M (1989) Sensitization of the startle reflex by footshock: blockade by lesions of the central nucleus of the amygdala or its efferent pathway to the brainstem. Behav Neurosci 103:509-518.

Hopkins DA, Holstege G (1978) Amygdaloid projections to the mesencephalon, pons and medulla oblongata in the cat. Exp Brain Res 32:529-547.

Huang Y-Y, Kandel ER (1998) Postsynaptic induction and PKAdependent expression of LTP in the lateral amygdala. Neuron 21:169-178.

Iwata J, LeDoux JE, Meeley MP, Arneric S, Reis DJ (1986) Intrinsic neurons in the amygdaloid field projected to by the medial geniculate body mediate emotional responses conditioned to acoustic stimuli. Brain Res 383:195-214.

Kapp BS, Frysinger RC, Gallagher M, Haselton JR (1979) Amygdala central nucleus lesions: effects on heart rate conditioning in the rabbit. Physiol Behav 23:1109-1117.

Krettek JE, Price JL (1977) Projections from the amygdaloid complex to the cerebral cortex and thalamus in the rat and cat. J Comp Neurol $172: 687-722$.

Krettek JE, Price JL (1978) A description of the amygdaloid complex in the rat and cat with observations on intra-amygdaloid axonal connections. J Comp Neurol 178:255-280.

Lang EJ, Paré D (1998) Synaptic responsiveness of interneurons of the cat lateral amygdaloid nucleus. Neuroscience 83:877-889.

LeDoux JE (1995) Emotion: clues from the brain. Annu Rev Psychol 46:209-235.

LeDoux JE, Ruggiero DA, Reis DJ (1985) Projections to the subcortical forebrain from anatomically defined regions of the medial geniculate body in the rat. J Comp Neurol 242:182-213.

LeDoux JE, Iwata J, Cicchetti P, Reis DJ (1988) Different projections of the central amygdaloid nucleus mediate autonomic and behavioral correlates of conditioned fear. J Neurosci 8:2517-2529.

LeDoux JE, Cicchetti P, Xagoraris A, Romanski LM (1990a) The lateral amygdaloid nucleus: sensory interface of the amygdala in fear conditioning. J Neurosci 10:1062-1069.

LeDoux JE, Farb C, Ruggiero DA (1990b) Topographic organization of neurons in the acoustic thalamus that project to the amygdala. J Neurosci 10:1043-1054.

Le Gal La Salle G, Paxinos G, Emson P, Ben-Ari Y (1978) Neurochemical mapping of GABAergic systems in the amygdaloid complex and bed nucleus of the stria terminalis. Brain Res 155:397-403.

Li H, Weiss SRB, Chuang D, Post RM, Rogawski MA (1998) Bidirectional synaptic plasticity in the rat basolateral amygdala: characterization of an activity-dependent switch sensitive to the presynaptic metabotropic glutamate receptor antagonist $2 S$ - $\alpha$-ethylglutamic acid. J Neurosci 18:1662-1670.

Llinás RR (1988) The intrinsic electrophysiological properties of mammalian neurons: insights into central nervous system function. Science 242:1654-1664.

Mahanty NK, Sah P (1998) Calcium-permeable AMPA receptors me- 
diate long-term potentiation in interneurons of the amygdala. Nature 394:683-687.

Mascagni F, McDonald AJ, Coleman JR (1993) Corticoamygdaloid and corticocortical projections of the rat temporal cortex: a Phaseolus vulgaris leucoagglutinin study. Neuroscience 57:697-715.

McDonald AJ (1985) Immunohistochemical identification of gammaaminobutyric acid-containing neurons in the rat basolateral amygdala. Neurosci Lett 53:203-207.

McDonald AJ (1992) Cell types and intrinsic connections of the amygdala. In: The amygdala: neurobiological aspects of emotion, memory, and mental dysfunction (Aggleton JP, ed), pp 67-96. New York: Wiley-Liss.

McDonald AJ, Augustine JR (1993) Localization of GABA-like immunoreactivity in the monkey amygdala. Neuroscience 52:281-294.

Millhouse OE (1986) The intercalated cells of the amygdala. J Comp Neurol 247:246-271.

Nitecka L, Ben-Ari Y (1987) Distribution of GABA-like immunoreactivity in the rat amygdaloid complex. J Comp Neurol 266:45-55.

Oleson TD, Westenberg IS, Weinberger NM (1972) Characteristics of the pupillary dilation response during pavlovian conditioning in paralyzed cats. Behav Biol 7:829-840.

Oleson TD, Vodonick DS, Weinberger NM (1973) Patterns of pupillary behavior in the paralyzed cat during inhibition of delay and differentiation. Behav Biol 8:903-911.

Oleson TD, Ashe JH, Weinberger NM (1975) Modification of auditory and somatosensory system activity during pupillary conditioning in the paralyzed cat. J Neurophysiol 38:1114-1139.

Pape HC, Driesang RB (1998) Ionic mechanisms of intrinsic oscillations in neurons of the basolateral amygdaloid complex. J Neurophysiol 79:217-226.

Pape HC, Paré D, Driesang RB (1998) Two types of intrinsic oscillations in neurons of the lateral and basolateral nuclei of the amygdala. J Neurophysiol 79:205-216.

Paré D, Gaudreau H (1996) Projection cells and interneurons of the lateral and basolateral amygdala: distinct firing patterns and differential relation to theta and delta rhythms in conscious cats. J Neurosci 16:3334-3350.

Paré D, Smith Y (1993a) Distribution of GABA immunoreactivity in the amygdaloid complex of the cat. Neuroscience 57:1061-1076.

Paré D, Smith Y (1993b) The intercalated cell masses project to the central and medial nuclei of the amygdala in cats. Neuroscience 57:1077-1090.

Paré D, Smith Y (1998) Intrinsic circuitry of the amygdaloid complex: common principles of organization in rats and cats. Trends Neurosci 21:240-241.

Paré D, Pape HC, Dong JM (1995a) Bursting and oscillating neurons of the cat basolateral amygdaloid complex in vivo: electrophysiological properties and morphological features. J Neurophysiol 74:1179-1191.

Paré D, Smith Y, Paré JF (1995b) Intra-amygdaloid projections of the basolateral and basomedial nuclei in the cat: Phaseolus vulgaris leucoagglutinin anterograde tracing at the light and electron microscopic level. Neuroscience 69:567-583.

Pascoe JP, Kapp BS (1985) Electrophysiological characteristics of amygdaloid central nucleus neurons in the awake rabbit. Brain Res Bull 14:331-338.

Petrovich GD, Risold PY, Swanson LW (1996) Organization of projec- tions from the basomedial nucleus of the amygdala: a PHAL study in the rat. J Comp Neurol 374:387-420.

Pitkänen A, Stefanacci L, Farb CR, Go GG, LeDoux JE, Amaral DG (1995) Intrinsic connections of the rat amygdaloid complex: projections originating in the lateral nucleus. J Comp Neurol 356:288-310.

Pitkänen A, Savander V, LeDoux JE (1997) Organization of intraamygdaloid circuitries in the rat: an emerging framework for understanding functions of the amygdala. Trends Neurosci 20:517-523.

Rainnie DG, Asprodini EK, Shinnick-Gallagher P (1993) Intracellular recordings from morphologically identified neurons of the basolateral amygdala. J Neurophysiol 69:1350-1362.

Savander V, Go CG, LeDoux JE, Pitkänen A (1995) Intrinsic connections of the rat amygdaloid complex: projections originating in the basal nucleus. J Comp Neurol 361:345-368.

Savander V, Go CG, LeDoux JE, Pitkänen A (1996) Intrinsic connections of the rat amygdaloid complex: projections originating in the accessory basal nucleus. J Comp Neurol 374:291-313.

Savander V, Miettinen R, LeDoux JE, Pitkänen A (1997) Lateral nucleus of the rat amygdala is reciprocally connected with basal and accessory basal nuclei: a light and electron microscopic study. Neuroscience 77:767-781.

Schiess MC, Asprodini EK, Rainnie DG, Shinnick-Gallagher P (1993) The central nucleus of the rat amygdala: in vitro intracellular recordings. Brain Res 604:283-297.

Smith Y, Paré D (1994) Intra-amygdaloid projections of the lateral nucleus in the cat: PHA-L anterograde labeling combined with postembedding GABA and glutamate immunocytochemistry. J Comp Neurol 342:232-248.

Stefanacci L, Farb CR, Pitkänen A, Go G, LeDoux JE, Amaral DG (1992) Projections from the lateral nucleus to the basal nucleus of the amygdala: a light and electron microscopic PHA-L study in the rat. J Comp Neurol 323:586-601.

Steriade M, Hobson JA (1976) Neuronal activity during the sleepwaking cycle. Prog Neurobiol 6:155-376.

Sun N, Cassell MD (1993) Intrinsic GABAergic neurons in the rat central extended amygdala. J Comp Neurol 330:381-404.

Sun N, Yi H, Cassell MD (1994) Evidence for a GABAergic interface between cortical afferents and brainstem projection neurons in the rat central extended amygdala. J Comp Neurol 340:43-64.

Turner BH, Herkenham M (1991) Thalamoamygdaloid projections in the rat: a test of the amygdala's role in sensory processing. J Comp Neurol 313:295-325.

Veening JG, Swanson LW, Sawchenko PE (1984) The organization of projections from the central nucleus of the amygdala to brainstem sites involved in central autonomic regulation: a combined retrograde transport-immunohistochemical study. Brain Res 303:337-357.

Washburn MS, Moises HC (1992) Electrophysiological and morphological properties of rat basolateral amygdaloid neurons in vitro. J Neurosci 12:4066-4079.

Weinberger NM, Hopkins W, Diamond DM (1984) Physiological plasticity of single neurons in the auditory cortex of the cat during acquisition of the pupillary conditioned response: I-Primary field (AI). Behav Neurosci 98:171-188.

Zhang JX, Harper RM, Ni H (1986) Cryogenic blockade of the central nucleus of the amygdala attenuates aversively conditioned blood pressure and respiratory responses. Brain Res 386:136-145. 